\title{
Lise Öğrencilerinde Sosyal Görünüş Kaygısı ve Fiziksel Aktiviteye Katılım Motivasyonu İlişkisi*
}

\author{
Sonnur KÜÇÜK KILIÇ \\ Erzincan Binali Ylldırım Üniversitesi, Eğitim Fakültesi, ORCID NO: 0000-0002-0355-0492
}

Geliş:17 Kasım 2020

Kabul:26 Aralik 2020

\begin{abstract}
ÖZ
$\mathrm{Bu}$ araştırmanın amacı, lise öğrencilerinin sosyal görünüş kaygısı ve fiziksel aktiviteye katılım motivasyonu düzeylerini bazı değişkenlere göre incelemek ve aralarındaki ilişkiyi belirlemektir. Araştırmanın çalışma grubunu, Ağrı ve Erzincan illerinde yer alan liselerde öğrenim gören 337 kız öğrenci oluşturmaktadır. Veri toplama aracı olarak "Sosyal Görünüș Kaygısı Ölçeği (SGKÖ)" ve "Fiziksel Aktiviteye Katılım Motivasyonu Ölçeği (FAKMÖ)" kullanılmıştır. Verilerin analizinde; betimsel istatistik yöntemler, t-testi, ANOVA ve Pearson Korelasyon testleri kullanılmıştır. Katılımcıların sosyal görünüş kaygıları düşük düzeyde, fiziksel aktiviteye katılım motivasyonu algıları ise orta seviyenin üzerindedir. Öğrencilerin sosyal görünüş kaygısı düzeyleri sınıf ve okul takımında yer alma durumu değişkenlerine göre anlamlı bir şekilde farklılaşmazken, fiziksel aktiviteye katılım motivasyonu algıları ise anlamlı bir şekilde farklılaşmaktadır. Katılımcıların sosyal görünüş kaygısı ve fiziksel aktiviteye katılım motivasyonu algıları gelir, anne eğitim durumu ve baba eğitim durumu değişkenlerine göre anlamlı bir şekilde farklılaşmamaktadır. Diğer yandan SGKÖ ve FAKMÖ'den alınan puanlar arasındaki korelasyon katsayısı, sosyal görünüş kaygısı ve fiziksel aktiviteye katılım motivasyonunun 'Nedensizlik' alt boyutunda negatif yönde ve orta düzeyde anlamlı bir ilişki olduğunu göstermektedir.
\end{abstract}

Anahtar Kelimeler: Sosyal görünüş, kaygı, fiziksel aktivite, motivasyon, lise öğrencisi

\section{Relationship Between Social Appearance Anxiety and Motivation for Participation in Physical Activity Among High School Students}

\begin{abstract}
The aim of this research was to examine social appearance anxiety and motivation for participation in physical activity levels of high students according to some demographic variables and determine the relation between them. A sample of 337 females students who studying at high schools in Ağrı and Erzincan provided responses. "Social Appearance Anxiety Scale (SAAS)" and "Motivation Scale for Participation in Physical Activity (MSPPA)" were administered on the participants. Descriptive statistical methods, t-test, ANOVA and Pearson Correlation analyses were used in the data analysis. Social appearance anxiety of the participants was at low level and motivation for physical activity participation were above the middle level. While the participants' social appearance anxiety perception did not differ significantly according the grade level and participating school sport team variables, motivation for physical activity participation perceptions differed significantly. Participants' perception of social appearance anxiety and motivation to participate in physical activity did not differ significantly according to income, mother education status and father education status variables. In addition, middle and negative correlation was observed between social appearance anxiety and motivation for physical activity participation.
\end{abstract}

Key Words: Social appearance, anxiety, physical activity, motivation, high school student

\footnotetext{
* Bu çalışmanın özeti International Symposium on Active Learning-ISAL2019 (6-8 Eylül, 2019, Adana)'da sözlü bildiri olarak sunulmuştur. ${ }^{1}$ Corresponding Authors Address: Erzincan Binali Yıldırım Üniversitesi, Eğitim Fakültesi, Beden Eğitimi ve Spor Bölümü, Merkez, Erzincan

e-mail: sonnur.kucukkilic@erzincan.edu.tr
} 


\section{Giriş}

Günümüzde bireylerin dış görünüşlerine giderek daha fazla önem verdikleri ve beden algısı ile ilgili sahip olunan tutumun bireyin psikolojisi üzerinde önemli etkilere sahip olduğu belirtilmektedir (Kring, Davison, Neale ve Johnson, 2015). Bu bağlamda yapılan çalışmalar, olumlu beden algısına sahip olmanın, özgüven ve sosyalliği arttırdığı, toplum karşısında bireyin kendini daha rahat hissetmesini sağladığı, ayrıca arkadaş edinmede de etkili olduğunu göstermektedir (Clark ve Tiggemann, 2006; Erdoğan ve Tütüncü, 2015; Kalafat, 2006; Matera, Nerini ve Stefanile, 2013; Tarhan, 1995; Y1lmaz, 2015). Bu durumun aksine olumsuz beden algısına sahip bireylerin ise daha çok içe kapanık, sosyal durumlarda yetersiz, karamsar ve kendine güveni olmayan, sürekli çevresinden onay arayan kişilik özelliklerine sahip oldukları ifade edilmektedir (Çınar ve Keskin, 2015). Bireyin bedeni ve fiziksel görünüşüyle ilgili olumsuz tutuma sahip olması ise sosyal görünüş kaygısı olarak tanımlanmaktadır (Doğan, 2010). Genel fiziksel görünüşün yanı sıra bireyin ten rengi ve yüz şekli gibi beden algısı ve beden imajına dair özellikleri de içeren kapsamlı bir kavram olan sosyal görünüş kaygısı (Hart, Flora, Palyo, Fresco, Holle ve Heimberg, 2008), sosyal etkileşimde bulunmaktan kaçınma (Crome, Grove, Baillie, Sunderland, Teesson ve Slade, 2015; Mills, Grant, Judah ve Lechner, 2014; Norton, Abbott, Norberg ve Hunt, 2015), başkaları tarafından olumsuz değerlendirilme (Bilge ve Keçecioğlu, 2008; Eren Gümüş, 2010) ve eleştirilme korkusu (Koyuncu, 2012) şeklinde ifade edilmektedir.

Sosyal görünüş kaygısının daha erken ya da daha geç yaşlarda ortaya çıkabileceği gibi genel olarak ergenliğin başlangıcında ortaya çıktığı görülmektedir (Leahy ve Holland, 2009). Ergenlik dönemi kimlik kazanımının ortaya çıktığı, bireyin kendisi ile diğerleri arasındaki ilişkileri sonucu kurduğu psiko-sosyal dengeyle çeşitli kimlik statülerinin kazanıldığı bir gelişim dönemidir (Demir, 2009). Bu dönemin temel özellikleri arasında yer alan dış görünüşe önem verme durumu çevresel faktörlerin de etkisiyle ergen için oldukça önemli hale gelmekte ve dış görünümündeki kusur ergen için önemli bir sorun olmaktadır (Doğan, 2011). Özellikle fiziksel görünüşlerine yönelik olumsuz düşüncelere sahip olan ve başkalarının kendi görünüşü hakkında olumsuz değerlendirmelerine daha duyarlı olan kişilerin kronik olarak sosyal görünüş kaygısı yaşadığı ifade edilmektedir (Hart, Leary ve Rejeski, 1989). Bu bağlamda bireylerin sosyal görünüş kaygılarını azaltmada fiziksel aktiviteye katılımlarını sağlamanın etkili olabileceği söylenebilir. Nitekim yapılan çalışmalar fiziksel aktiviteye katılımın bireylerin 
sosyal görünüş kaygısını azalttığını göstermektedir (Alemdağ ve Öncü, 2015; Özdemir, Çuğ ve Çelik, 2010).

Bireylerin sağlığı üzerinde birçok olumlu etkiye sahip olan düzenli fiziksel aktiviteye katılımın ruh sağlığı ve sosyal gelişim açısından da depresyon ve kaygı bozukluğu riskini azalttı̆̆ bilinmektedir (Türkiye Fiziksel Aktivite Rehberi, 2014). Öte yandan yapılan çalışmalar fiziksel aktivitenin çocukların ve ergenlerin ruh sağlığı ve psikolojik iyilik hali üzerine yararlarını bilimsel olarak kanıtlamakta ve özellikle 5-17 yaş çocuklar ve gençler için fiziksel aktivitenin önemli sağlık yararları olduğunu göstermektedir (Meydanlığlu, 2015). Ayrıca fiziksel aktivitenin, fiziksel benlik saygısı ve beden imgesi gibi benlik algılarını teşvik etmek ve psikolojik iyilik halini artırmak için önemli bir araç olarak kullanıldığı (Bingham, 2009'dan aktaran Meydanlığlu, 2015), bununla birlikte düzenli fiziksel aktivite yapan çocuklarda kendine güven, benlik saygısı ve yeterlik duygularının daha yüksek olduğu belirlenmiştir (Eime, Young, Harvey, Charity ve Payne, 2013).

Fiziksel aktiviteye katılımın belirtilen yararlarına rağmen tüm dünyada çocukların fiziksel aktiviteye katılım düzeylerinin oldukça düşük olduğu (CDC, 2010); özellikle ergenlik dönemiyle birlikte (10-16 yaşlar) fiziksel aktiviteye katılımın azaldığı ve azalmanın kızlarda daha çok olduğu ifade edilmektedir (Strauss, Rodzilsky, Burack ve Colin, 2001). Bunun yanı sıra yapılan çalışmalar genel kaygının (Beesdo, Knappe ve Pine, 2009; Görker, Korkmazlar, Durukan ve Aydoğdu, 2004; Schniering, Hudson ve Rapee, 2000; Verhulst, Ende, Ferdinand ve Kasius, 1997) yanı sıra sosyal görünüş kaygısı (Özkan, 2017; Seki, 2014; Şahin, 2018) ve olumsuz değerlendirilme korkusunun (Gültekin, 2019; Ümmet, Çağlar, İme ve Aky11, 2018) çocuklar ve ergenler arasında giderek yaygınlaşmaya başladığını göstermektedir. Bu bağlamda uzun vadede hem fiziksel hem de ruhsal anlamda sağlıklı nesiller yetiştirmek ve sağlıklı toplum oluşturmak, bugünün gençlerinin mevcut durumları ortaya koyularak sağlanabilir. Bu nedenle çalışmadan elde edilen sonuçların gençlerin sosyal görünüş kaygı düzeylerinin ve fiziksel aktiviteye katılım motivasyonu düzeylerinin belirlenmesi noktasında literatüre katk1 sağlayacağı düşünülmektedir. Buradan hareketle bu araştırmanın amacı lise öğrencilerinin sosyal görünüş kaygısı ve fiziksel aktiviteye katılım motivasyonu düzeylerini bazı değişkenlere göre incelemek ve aralarındaki ilişkiyi belirlemektir. Bu amaç doğrultusunda aşağıdaki sorulara yanıt aranmıştır:

1. Lise öğrencilerinin sosyal görünüş kaygısı ve spora katılım motivasyonları ne düzeydedir? 
2. Lise öğrencilerinin sosyal görünüş kaygısı ve spora katılım motivasyonları sınıf düzeyine göre anlamlı bir şekilde farklılaşmakta mıdır?

3. Lise öğrencilerinin sosyal görünüş kaygısı ve spora katılım motivasyonları aylık gelir değişkenine göre anlamlı bir şekilde farklılaşmakta mıdır?

4. Lise öğrencilerinin sosyal görünüş kaygısı ve spora katılım motivasyonları okul spor takımında yer alma durumuna göre anlamlı bir şekilde farklılaşmakta mıdır?

5. Lise öğrencilerinin sosyal görünüş kaygısı ve spora katılım motivasyonları anne eğitim durumuna göre anlamlı bir şekilde farklılaşmakta mıdır?

6. Lise öğrencilerinin sosyal görünüş kaygısı ve spora katılım motivasyonları baba eğitim durumuna göre anlamlı bir şekilde farklılaşmakta mıdır?

7. Lise öğrencilerinin sosyal görünüş kaygısı ve spora katılım motivasyonları arasında anlamlı bir ilişki var mıdır?

\section{Yöntem}

\section{Araştırma Modeli}

Araştırmada, araştırmaya konu olan birey ya da nesnenin kendi koşulları içinde var olduğu şekliyle tanımlanmaya çalışıldığı betimsel tarama modeli kullanılmıştır (Karasar, 2012). Araştırmada veri toplama tekniği olarak ise anket tekniği kullanılmıştır (Nachmias ve Nachmias, 1996).

\section{Araştırma Grubu}

Çalışmanın araştırma grubunu 2018-2019 eğitim-öğretim yılında Erzincan ve Ağrı illerinde yer alan iki farklı k1z meslek lisesinde öğrenim gören ve kolayda örnekleme yöntemi ile seçilen 337 kı öğrenci oluşturmuştur. Katılımcıların 178’i (\%52.8) Ağrı ilinde ve 159’u (\%47.2)'si de Erzincan ilindeki liselerde öğrenim görmektedir. Katılımcılardan 71'i dokuzuncu sınıf, 167'si onuncu sınıf, 70'i on birinci sınıf ve 29'u da on ikinci sınıfta öğrenim gördüklerini belirtmişlerdir. Ayrıca katılımcıların 109'u okul spor takımında yer aldığını; 228'i ise okul spor takımlarında yer almadığını ifade etmişlerdir.

\section{Veri Toplama Araçları}

\section{Kişisel Bilgi Formu:}

Araştırmacı tarafından geliştirilen kişisel bilgi formu araştırmaya konu olan lise öğrencileri hakkında bilgi toplamak amacıyla sınıf, gelir, anne ve baba eğitim durumu, okul 
spor takımlarında yer alma durumu ile ilgili bağımsız değişkenlerle ilgili sorulardan oluşmaktadır.

\section{Sosyal Görünüş Kaygısı Ölçeği (SGKÖ):}

Çalışmaya katılan lise öğrencilerinin sosyal görünüş kaygısı düzeylerini ölçmek amacıyla La Greca ve Lopez (1998) tarafından geliştirilen, Doğan (2011) tarafından Türkçeye uyarlanan “Sosyal Görünüş Kaygısı Ölçeği (SGKÖ)" kullanılmıştır. Ölçek 16 maddeden oluşmakta ve 5'li Likert tipinde puanlanmaktadır. Ölçekte yer alan 1. madde tersten kodlanmaktadır. Ölçeğin bu araştırma kapsamında toplanan veriler üzerinde hesaplanan Cronbach Alpha iç tutarlık katsayıs ise $0.88^{\prime}$ dir.

\section{Fiziksel Aktiviteye Katılım Motivasyonu Ölçeği (FAKMÖ):}

Öğrencilerin fiziksel aktiviteye katılım motivasyonlarını ölçmek amacıyla Tekkurşun ve Cicioğlu (2018) tarafından geliştirilen "Fiziksel Aktiviteye Katılım Motivasyonu Ölçeği (FAKMÖ)" kullanılmıştır. Ölçek 16 madde ve 3 alt boyuttan oluşmakta ve 5'li Likert tipinde puanlanmaktadır. Ölçek faktörler Bireysel Nedenler (6 madde), Çevresel Nedenler (6 madde) ve Nedensizlik (4 madde) şeklindedir. Bireysel Nedenler, kişinin kendi isteği, arzusu ve keyif alacağını düşündüğü durumlar doğrultusunda harekete geçmesini sağlayan nedenler olarak ifade edilirken, Çevresel Nedenler kişinin çevresel faktörlerden etkilenmesi ile yapacağ aktiviteyi veya amacı gerçekleştirmek için harekete geçmesini sağlayan nedenler olarak belirtilmektedir. Bir diğer alt boyut olan Nedensizlik ise, kişinin yapacağı bir aktiviteyi neden yapacağına ya da sonucunda ne olacağına ilişkin belirsiz duygu hali şeklinde ifade edilmektedir (Tekkurşun ve Cicioğlu, 2018). Ölçeğin bu araştırma kapsamında toplanan veriler üzerinde hesaplanan Cronbach Alpha iç tutarlık katsayıları ise Bireysel Nedenler için 0.84, Çevresel Nedenler için 0.72 , Nedensizlik için 0.72 ' dir.

\section{Veri Toplama Süreci}

Çalışma kapsamında kullanılan veri toplama araçları, 2018-2019 eğitim-öğretim yılında gerekli izinlerin alınmasından sonra araştırma grubunu oluşturan lise öğrencilerine ders saatlerinden önce uygulanmıştır. Anket formunda çalışmaya katılmanın gizlilik ve gönüllülük esasına dayandığı özellikle belirtilmiş, ayrıca uygulama öncesinde de konu ile ilgili detaylı açıklamalar yapılarak katılmak istemeyen öğrenciler çalışma dışında tutulmuştur. Öğrencilerin ölçekleri doldurması ise yaklaşık 15 dakika sürmüştür. Toplanan anket formları kontrol edilerek eksik veya hatalı doldurulan anketler çalışmaya dâhil edilmemiştir. 


\section{Verilerin Analizi}

Araştırmada toplanan verilerin analizinde, betimsel istatistik yöntemler (frekans, aritmetik ortalama, standart sapma), t-testi, tek yönlü varyans analizi (ANOVA), Tukey çoklu karşılaştırma ve Pearson Korelasyon testleri kullanılmıştır. Verilerin parametrik testlerin ön şartlarını sağlayıp sağlamadığına Skewness ve Kurtosis (verilerin normal dağılım durumu) değerleri ve Levene (varyansların eşitliği) testi sonuçları incelenerek karar verilmiştir (Büyüköztürk, 2012). Ayrıca ölçeklerin güvenirliklerini belirlemek için de Cronbach Alpha iç tutarlık kat sayıları hesaplanmıştır. Çalışmada anlamlılık düzeyi 0.05 olarak alınmıştır.

\section{Bulgular}

Çalışma kapsamındaki katılımcıların Sosyal Görünüş Kaygısı Ölçeği (SGKÖ)'nden aldıkları toplam puanların aritmetik ortalaması 2.41 ve standart sapması 0.86 'dır. Öğrencilerin Fiziksel Aktiviteye Katılım Motivasyonu Ölçeği (FAKMÖ)'nden aldıkları toplam puanların aritmetik ortalaması 3.54 ve standart sapması ise 0.72 'dir. FAKMÖ puanları faktör bazında incelendiğinde en yüksek ortalamanın Bireysel Nedenler (Ort=3.69), en düşük ortalamanın ise Çevresel Nedenler (Ort=3.41) alt boyutunda olduğu görülmektedir. Ölçeklerden alınan puanların çarpıklık ve basıklık değerleri incelendiğinde verilerin normal dağılım gösterdiği söylenebilir (Tablo 1).

Tablo 1

Ölçek Puanlarının Dağılımı

\begin{tabular}{lccccccc}
\hline & $\begin{array}{c}\text { Madde } \\
\text { Sayısı }\end{array}$ & Ort. & Ss & Çarpıklık & Basıklık & Min. & Mak. \\
\hline SGKÖ & 16 & 2.41 & 0.86 & 0.48 & -0.35 & 1.00 & 4.75 \\
\hline Bireysel Nedenler & 6 & 3.69 & 0.95 & -0.66 & -0.10 & 1.00 & 5.00 \\
\hline Çevresel Nedenler & 6 & 3.41 & 0.87 & -0.19 & -0.37 & 1.00 & 5.00 \\
\hline Nedensizlik & 4 & 3.52 & 0.92 & -0.26 & -0.26 & 1.00 & 5.00 \\
\hline FAKMÖ & 16 & 3.54 & 0.72 & -0.19 & -0.03 & 1.19 & 5.00 \\
\hline
\end{tabular}

Tablo 2'te katılımcıların SGKÖ ve FAKMÖ'nin alt boyutlarından aldıkları puanların sınıf değişkenine göre ANOVA sonuçları sunulmuştur. Öğrencilerin sınıf değişkenine göre SGKÖ puanlarının anlamlı bir şekilde farklılaşmadığı tespit edilmiştir $\left(\mathrm{F}_{(3,333)}=0.28, \mathrm{p}>0.05\right)$. Kat1lımc1ların toplam FAKMÖ $\left(\mathrm{F}_{(3,333)}=5.58, \mathrm{p}<0.01\right)$ ve Bireysel Nedenler $\left(\mathrm{F}_{(3,333)}=5.61\right.$, 
$\mathrm{p}<0.01)$ ile Çevresel Nedenler $\left(\mathrm{F}_{(3,333)}=4.81, \mathrm{p}<0.01\right)$ alt boyut puanlarının anlamlı bir şekilde farklılaştığı, Nedensizlik alt boyut puanlarının ise anlamlı bir şekilde farklılaşmadığı belirlenmiştir $\left(\mathrm{F}_{(3,333)}=0.59, \mathrm{p}>0.05\right)$. Bu bulguya göre 11. sinıfta öğrenim gören öğrencilerin puanları 9, 10 ve 11. sınıfta öğrenim gören öğrencilerin puanlarından daha yüksektir.

Tablo 2

Sınıf Değişkenine Göre ANOVA Sonuçları

\begin{tabular}{|c|c|c|c|c|c|c|c|c|c|c|c|}
\hline & \multicolumn{2}{|c|}{$\begin{array}{l}\text { 9. sinif } \\
(n=71)\end{array}$} & \multicolumn{2}{|c|}{$\begin{array}{l}\text { 10. sin1f } \\
(n=167)\end{array}$} & \multicolumn{2}{|c|}{$\begin{array}{c}\text { 11. sinif } \\
(n=70)\end{array}$} & \multicolumn{2}{|c|}{$\begin{array}{l}\text { 12. sinif } \\
(n=29)\end{array}$} & \multirow[b]{2}{*}{$\mathbf{F}$} & \multirow[b]{2}{*}{$\mathbf{p}$} & \multirow[b]{2}{*}{ Anlamlı } \\
\hline & Ort & Ss & Ort & Ss & Ort & Ss & Ort & Ss & & & \\
\hline SGKÖ & 2.39 & 0.86 & 2.45 & 0.85 & 2.35 & 0.85 & 2.36 & 1.00 & 0.28 & 0.84 & - \\
\hline Bireysel Nedenler & 3.53 & 1.05 & 3.69 & 0.90 & 4.03 & 0.87 & 3.29 & 0.91 & 5.61 & 0.00 & $11>9,10,12$ \\
\hline Çevresel Nedenler & 3.32 & 0.90 & 3.34 & 0.85 & 3.75 & 0.83 & 3.22 & 0.81 & 4.81 & 0.00 & $11>9,10,12$ \\
\hline Nedensizlik & 3.46 & 0.95 & 3.51 & 0.85 & 3.65 & 1.05 & 3.46 & 0.89 & 0.59 & 0.62 & - \\
\hline$F A K M \ddot{O}$ & 3.43 & 0.78 & 3.51 & 0.67 & 3.83 & 0.74 & 3.31 & 0.59 & 5.58 & 0.00 & $11>9,10,12$ \\
\hline
\end{tabular}

Tablo 3'te katılımcıların SGKÖ ve FAKMÖ'nin alt boyutlarından aldıkları puanların aylık gelir değişkenine göre ANOVA sonuçları sunulmuştur. Öğrencilerin aylık gelir değişkenine göre SGKÖ $\left(\mathrm{F}_{(2,334)}=0.45, \mathrm{p}>0.05\right)$ ile toplam FAKMÖ $\left(\mathrm{F}_{(2,334)}=0.30, \mathrm{p}>0.05\right)$ ve Bireysel Nedenler $\left(\mathrm{F}_{(2,334)}=0.42, \mathrm{p}>0.05\right)$, Çevresel Nedenler $\left(\mathrm{F}_{(2,334)}=0.38, \mathrm{p}>0.05\right)$ ve Nedensizlik $\left(\mathrm{F}_{(2,334)}=0.06, \mathrm{p}>0.05\right)$ alt boyut puanlarının anlamlı bir şekilde farklılaşmadı $\breve{g}_{1}$ tespit edilmiştir.

Tablo 3

Aylık Gelir Değişkenine Göre ANOVA Sonuçları

\begin{tabular}{|c|c|c|c|c|c|c|c|c|}
\hline & \multicolumn{2}{|c|}{$\begin{array}{c}1000 \text { TL ve alt } 1 \\
(n=110)\end{array}$} & \multicolumn{2}{|c|}{$\begin{array}{c}1001-2000 \mathrm{TL} \\
(n=90)\end{array}$} & \multicolumn{2}{|c|}{$\begin{array}{c}2001 \text { TL ve üzeri } \\
(n=137)\end{array}$} & \multirow[b]{2}{*}{$\mathbf{F}$} & \multirow[b]{2}{*}{$\mathbf{p}$} \\
\hline & Ort. & Ss & Ort. & Ss & Ort. & Ss & & \\
\hline SGKÖ & 2.47 & 0.86 & 2.39 & 0.93 & 2.37 & 0.82 & 0.45 & 0.64 \\
\hline Bireysel Nedenler & 3.67 & 0.93 & 3.77 & 0.97 & 3.66 & 0.96 & 0.42 & 0.66 \\
\hline Çevresel Nedenler & 3.45 & 0.83 & 3.44 & 0.90 & 3.36 & 0.88 & 0.38 & 0.69 \\
\hline Nedensizlik & 3.50 & 0.84 & 3.54 & 0.96 & 3.52 & 0.95 & 0.06 & 0.94 \\
\hline$F A K M \ddot{O}$ & 3.55 & 0.70 & 3.59 & 0.71 & 3.51 & 0.75 & 0.30 & 0.74 \\
\hline
\end{tabular}

Tablo 4'te öğrencilerin SGKÖ ve FAKMÖ'den aldıkları puanların okul spor takımlarında yer alma değişkenine göre t-testi sonuçları sunulmuştur. Analizler, okul spor takımlarında yer alma durumu değişkenine göre SGKÖ puanlarının anlamlı bir şekilde 
farklılaşmadığını göstermektedir $(\mathrm{t}=1.66, \mathrm{p}>0.05)$. Diğer yandan katılımcıların toplam FAKMÖ $(\mathrm{t}=2.59, \mathrm{p}<0.05)$ ve Çevresel Nedenler $(\mathrm{t}=2.30, \mathrm{p}<0.05)$ alt boyut puanlarının anlamlı bir şekilde farklılaştığı, Bireysel Nedenler $(\mathrm{t}=2.00, \mathrm{p}>0.05)$ ve Nedensizlik $(\mathrm{t}=2.01, \mathrm{p}=0.05)$ puanlarının ise anlamlı bir şekilde farklılaşmadığ 1 tespit edilmiştir. Buna göre okul spor takımlarında yer alan öğrencilerin fiziksel aktiviteye katılım motivasyonlarının katılmayan öğrencilerden daha yüksek olduğu söylenebilir.

Tablo 4

Okul Spor Takımlarında Yer Alma Durumu Değişkenine Göre t-Testi Sonuçları

\begin{tabular}{lcccccc}
\hline & \multicolumn{2}{c}{$\begin{array}{c}\text { Evet } \\
(n=109)\end{array}$} & \multicolumn{2}{c}{$\begin{array}{c}\text { Hayır } \\
(n=228)\end{array}$} & \\
\hline & Ort. & Ss & Ort. & Ss & t & p \\
\hline SGKÖ & 2.52 & 0.92 & 2.36 & 0.83 & 1.66 & 0.10 \\
\hline Bireysel Nedenler & 3.84 & 1.02 & 3.62 & 0.91 & 2.00 & 0.05 \\
\hline Çevresel Nedenler & 3.58 & 0.96 & 3.33 & 0.81 & 2.30 & 0.02 \\
\hline Nedensizlik & 3.67 & 0.97 & 3.45 & 0.89 & 2.01 & 0.05 \\
\hline FAKMÖ & 3.70 & 0.79 & 3.47 & 0.67 & 2.59 & 0.01 \\
\hline
\end{tabular}

Tablo 5'te katılımcıların SGKÖ ve FAKMÖ'nin alt boyutlarından aldıkları puanların anne eğitim durumu değişkenine göre ANOVA sonuçları sunulmuştur. Öğrencilerin anne eğitim durumu değişkenine göre SGKÖ $\left(\mathrm{F}_{(2,334)}=0.92, \mathrm{p}>0.05\right)$ ile toplam FAKMÖ $\left(\mathrm{F}_{(2,334)}=0.77, \mathrm{p}>0.05\right) \quad$ ve Bireysel Nedenler $\left(\mathrm{F}_{(2,334)}=0.69, \mathrm{p}>0.05\right)$, Çevresel Nedenler $\left(\mathrm{F}_{(2,334)}=0.32, \mathrm{p}>0.05\right)$ ve Nedensizlik $\left(\mathrm{F}_{(2,334)}=0.65, \mathrm{p}>0.05\right)$ alt boyut puanlarının anlamlı bir şekilde farklılaşmadığı tespit edilmiştir.

Tablo 5

Anne Ĕ̆itim Durumu Değişkenine Göre ANOVA Sonuçlart

\begin{tabular}{|c|c|c|c|c|c|c|c|c|}
\hline & \multicolumn{2}{|c|}{$\begin{array}{c}\text { İlkokul ve alt1 } \\
(n=233)\end{array}$} & \multicolumn{2}{|c|}{$\begin{array}{c}\text { Ortaokul } \\
(n=72)\end{array}$} & \multicolumn{2}{|c|}{$\begin{array}{c}\text { Lise ve üzeri } \\
(n=32)\end{array}$} & \multirow[b]{2}{*}{$\mathbf{F}$} & \multirow[b]{2}{*}{$\mathbf{p}$} \\
\hline & Ort. & Ss & Ort. & Ss & Ort. & Ss & & \\
\hline SGKÖ & 2.39 & 0.88 & 2.53 & 0.77 & 2.32 & 0.92 & 0.92 & 0.40 \\
\hline Bireysel Nedenler & 3.65 & 0.96 & 3.78 & 0.93 & 3.80 & 0.92 & 0.69 & 0.50 \\
\hline Çevresel Nedenler & 3.39 & 0.89 & 3.48 & 0.84 & 3.43 & 0.83 & 0.32 & 0.73 \\
\hline Nedensizlik & 3.49 & 0.91 & 3.56 & 0.89 & 3.67 & 1.03 & 0.65 & 0.53 \\
\hline FAKMÖ & 3.51 & 0.73 & 3.61 & 0.66 & 3.63 & 0.77 & 0.77 & 0.46 \\
\hline
\end{tabular}


Tablo 6'da katılımcıların SGKÖ ve FAKMÖ’nin alt boyutlarından aldıkları puanların baba eğitim durumu değişkenine göre ANOVA sonuçları sunulmuştur. Öğrencilerin baba eğitim durumu değişkenine göre SGKÖ $\left(\mathrm{F}_{(2,334)}=0.51, \mathrm{p}>0.05\right)$ ile toplam FAKMÖ $\left(\mathrm{F}_{(2,334)}=0.17, \mathrm{p}>0.05\right) \quad$ ve Bireysel Nedenler $\left(\mathrm{F}_{(2,334)}=0.01, \mathrm{p}>0.05\right)$, Çevresel Nedenler $\left(\mathrm{F}_{(2,334)}=0.36, \mathrm{p}>0.05\right)$ ve Nedensizlik $\left(\mathrm{F}_{(2,334)}=0.16, \mathrm{p}>0.05\right)$ alt boyut puanlarının anlamlı bir şekilde farklılaşmadı̆̆ tespit edilmiştir.

Tablo 6

Baba Ĕ̆itim Durumu Değişkenine Göre ANOVA Sonuçları

\begin{tabular}{lcccccccc}
\hline & \multicolumn{2}{c}{$\begin{array}{c}\text { İlkokul ve alt1 } \\
(n=138)\end{array}$} & \multicolumn{2}{c}{$\begin{array}{c}\text { Ortaokul } \\
(n=123)\end{array}$} & \multicolumn{2}{c}{$\begin{array}{c}\text { Lise ve üzeri } \\
(n=76)\end{array}$} \\
\cline { 2 - 10 } & Ort. & Ss & Ort. & Ss & Ort. & Ss & F & p \\
\hline SGKÖ & 2.47 & 0.87 & 2.36 & 0.85 & 2.39 & 0.86 & 0.51 & 0.60 \\
\hline Bireysel Nedenler & 3.69 & 0.98 & 3.69 & 0.90 & 3.71 & 0.96 & 0.01 & 1.00 \\
\hline Çevresel Nedenler & 3.36 & 0.92 & 3.44 & 0.84 & 3.45 & 0.82 & 0.36 & 0.70 \\
\hline Nedensizlik & 3.49 & 0.91 & 3.55 & 0.92 & 3.53 & 0.94 & 0.16 & 0.85 \\
\hline FAKMÖ & 3.52 & 0.78 & 3.56 & 0.66 & 3.57 & 0.71 & 0.17 & 0.84 \\
\hline
\end{tabular}

Tablo 7'de SGKÖ ve FAKMÖ alt boyut puanları arasındaki korelasyon sonuçları sunulmuştur. Sonuçlar, sosyal görünüş kaygısı ile fiziksel aktiviteye katılım motivasyonunun Nedensizlik alt boyutu arasında negatif yönde ve orta düzeyde $(\mathrm{r}=-0.35, \mathrm{p}<0.01)$ anlamlı bir ilişki olduğunu göstermektedir.

Tablo 7

SGKÖ ve FAKMÖ Puanları Arasındaki Korelasyon Sonuçları

\begin{tabular}{lccc}
\hline & \multicolumn{3}{c}{ SGKÖ } \\
\cline { 2 - 4 } & $\mathbf{n}$ & $\mathbf{r}$ & $\mathbf{p}$ \\
\hline Bireysel Nedenler & 337 & 0.01 & 0.90 \\
\hline Çevresel Nedenler & 337 & 0.01 & 0.92 \\
\hline Nedensizlik & 337 & -0.35 & 0.00 \\
\hline FAKMÖ & 337 & -0.10 & 0.06 \\
\hline${ }^{* *} \mathrm{p}<0.01$ & & &
\end{tabular}

\section{Tartış̧ma}

Lise öğrencilerinin sosyal görünüş kaygısı ve fiziksel aktiviteye katılım motivasyonu düzeylerini bazı değişkenlere göre incelemek ve aralarındaki ilişkiyi belirlemek amacıyla 
yürütülen bu çalışmadan elde edilen veriler bu bölümde tartışılmış ve yorumlanmaya çalışılmıştır.

Çalışma sonucunda katılımcıların sosyal görünüş kaygılarının Kılıç ve Karakuş (2016), Senna (2019) ve Yüceant (2013) tarafından yapılan çalışmaların sonuçlarına paralel olarak düşük düzeyde olduğu tespit edilmiştir. Bunun yanı sıra literatürde yer alan bazı çalışmalarda katılımcıların sosyal görünüş kaygılarının orta seviyede olduğu tespit edilmiştir (Arslan, 2019; Kalemoğlu Varol, Erbaş ve Ünlü, 2014; Vural, Keskin ve Çoruh, 2017). Araştırma sonucunda katılımcıların fiziksel aktiviteye katılım motivasyonu algılarının orta seviyenin üzerinde olduğu belirlenmiştir. Literatürde yer alan bazı çalışmalarda ise katılımcıların fiziksel aktiviteye katılım motivasyonlarının yüksek düzeyde olduğu belirlenmiştir (Tekkurşun Demir ve Cicioğlu, 2019; Tekkurşun Demir ve İlhan, 2019; Türkeli ve Namlı, 2019). Çalışmada yer alan katılımcıların sosyal görünüş kaygılarının düşük çıkmasının sebebi öğrenim gördükleri lise türü ile ilgili olabilir. Çalışmanın kız meslek lisesinde öğrenim gören öğrenciler üzerinde yürütülmesi ve bu liselerde genellikle kız öğrencilerin öğrenim görüyor olması bu sonucun ortaya çıkmasında etkili olabilir. Nitekim özellikle büyüme çağındaki bireylerin beden yapılarının ve dış görünüşlerinin karşı cinsin hoşuna gidecek biçimde olmasını arzulamalarının yaygın bir istek olduğu ve bu durumun da sosyal görünüş kaygısı ile sonuçlanabileceği belirtilmektedir (Kulaksızoğlu, 2011). İlerde yapılacak çalışmalarda özellikle karma eğitim veren kurumlar ile tek cinsiyetli eğitim veren kurumlarda öğrenim gören öğrenciler karşılaştırılarak bu sonucun ortaya çıkmasındaki neden daha somut bir şekilde ortaya konulabilir.

Çalışmadan elde edilen sonuçlara göre öğrencilerin sosyal görünüş kaygısı düzeyleri sınıf değişkenine göre anlamlı bir şekilde farklılaşmamaktadır. Benzer şekilde literatürde yer alan bazı çalışmalarda da sosyal görünüş kaygısının sınıf değişkenine göre farklılaşmadığı belirlenmiştir (Yüceant, 2013). Özkan (2017) tarafından yapılan çalışmada ise sosyal görünüş kaygısının sınıf değişkenine göre farklılaştı̆̆ı ve 10. sınıfta öğrenim gören öğrencilerin en yüksek sosyal görünüş kaygısı düzeyine sahip olduğu belirlenmiştir. Öte yandan literatürde sosyal görünüş kaygısını yaş değişkeni açısından inceleyen çalışmaların sonuçlarına bakıldığında, bazı çalışmalarda sosyal görünüş kaygısının yaşa göre değişmediği (Karacabey, Apur, Öntürk ve Akyel, 2017; Soylu, Atik ve Öçalan, 2017; Türker, Yavuz Eroğlu, Şentürk ve Durmaz, 2018; Yüceant, 2013); bazılarında ise yaş büyüdükçe sosyal görünüş kaygısının arttığı sonucuna ulaşılmıştır (Alımcı, 2018). Bunun yanı katılımcıların fiziksel aktiviteye katılım 
motivasyonlarının sınıf değişkenine göre anlamlı bir şekilde farklılaşmadığı çalışmanın sonuçları arasında yer almaktadır. Benzer şekilde Kahıyah ve Yarım (2020), Mutlu Bozkurt ve Tamer (2020) ile Türkeli ve Namlı (2019) tarafından yapılan çalışmalarda da katılımcıların fiziksel aktiviteye katılım motivasyonlarının sınıfa göre farklılaşmadığı belirlenmiştir. Öte yandan yapılan bazı çalışmalarda 10. sınıfta öğrenim gören katılımcıların fiziksel aktiviteye katılım motivasyonlarının 12. sınıf ve 9. sınıfta öğrenim görenlerden daha yüksek olduğu belirlenmiştir (Tekkurşun Demir ve Cicioğlu, 2019). Literatürde yer alan farklı bir çalışmada ise katılımcıların fiziksel aktiviteye katılım motivasyonları sınıf düzeyine göre incelendiğinde bireysel nedenler alt boyutunda 12. sınıfların; nedensizlik boyutunda ise 11. sınıf öğrencilerinin puanlarının daha düşük olduğu saptanmıştır (Çakır, 2019). Araştırmada yer alan katılımcıların yaşları dikkate alındığında ergenlikle birlikte ortaya çıkan bedensel değişimlere uyum sağlamış oldukları düşünülebilir. Bu durumun da sosyal görünüş kaygısının sınıfa göre değişmemesine neden olduğu söylenebilir.

Çalışmadan elde edilen bir diğer sonuca göre öğrencilerin sosyal görünüş kaygısı düzeyleri okul takımında yer alma durumuna göre anlamlı bir şekilde farklılaşmamaktadır. Vatansever (2017) tarafindan yapılan çalışmada spor yapan katılımcıların sosyal görünüş kaygıları düşük olduğu; Soylu vd. (2017) tarafından yapılan çalışmada ise spor yapan bireylerin sosyal görünüş kaygılarının yüksek olduğu tespit edilmiştir. Sosyal görünüş kaygısından elde edilen bulgulara benzer şekilde katılımcıların fiziksel aktiviteye katılım motivasyonu algılarının da okul takımında yer alma durumuna göre anlamlı bir şekilde farklılaşmadığı belirlenmiştir. Literatürde yer alan bir çalışmada ise okul takımında yer almayan öğrencilerin fiziksel aktiviteye katılım motivasyonu bireysel nedenler alt boyut puanlarının daha düşük olduğu belirlenmiştir (Mutlu Bozkurt ve Tamer, 2020).

Çalışma sonucunda Çetinkaya, Gülaçtı ve Çiftçi (2019), Kılıç ve Karakuş (2016) ve Yüceant (2013) tarafından yapılan çalışmaların sonuçlarına paralel olarak sosyal görünüş kaygısının gelir durumuna göre anlamlı bir şekilde farklılaşmadığı belirlenmiştir. Öte yandan Alımcı (2018), Arslan (2019) ve Şahin (2018) tarafından yapılan çalışmalarda ise gelir durumu yüksek olanların sosyal görünüş kaygılarının düşük olduğu tespit edilmiştir. Bunun yanı sıra çalışmada yer alan öğrencilerin fiziksel aktiviteye katılım motivasyonu algılarının da gelire göre anlamlı bir şekilde farklılaşmadığı belirlenmiştir. Üniversite öncesi öğrenimde öğrencilerin özellikle ikamet yerlerine yakın okullarda öğrenim görmeleri ve benzer sosyoekonomik düzeye sahip çevrede yaşamaları bu sonucun ortaya çıkmasında etkili olabilir. Daha sonra yapılacak çalışmalarda özellikle farklı sosyo-ekonomik düzeye sahip çevrede ikamet 
eden öğrencilerin karşılaştırılması sonucun daha net bir şekilde yorumlanmasına katkı sağlayabilir.

Katılımcıların sosyal görünüş kaygısı düzeyleri anne eğitim durumuna göre anlamlı bir şekilde farklılaşmamaktadır. Literatürde yer alan bazı çalışmalarda da sosyal görünüş kaygısının anne eğitim durumuna göre farklılaşmadığı belirlenmiştir (Alımcı, 2019; Çetinkaya vd., 2019; Şahin, 2018). Özkan (2017) tarafından yapılan çalışmada ise anne eğitim durumu okur-yazar olmayan katılımcıların sosyal görünüş kaygısı düzeylerinin, anne eğitim durumu lise ve üniversite olan katılımcılardan daha yüksek olduğu sonucuna ulaşılmıştır. Öte yandan çalışma sonucunda öğrencilerin fiziksel aktiviteye katılım motivasyonu algılarının anne eğitim durumuna göre farklılaşmadığı saptanmıştır. Benzer şekilde Kahıyah ve Yarım (2020) ile Mutlu Bozkurt ve Tamer (2020) tarafından yapılan çalışmalarda da katılımcıların fiziksel aktiviteye katılım motivasyonları anne eğitim durumuna göre farklılaşmamaktadır. Fiziksel aktiviteye katılımda anne eğitim düzeyinin yanı sıra annenin fiziksel aktiviteye yönelik tutumunun etkili olduğu söylenebilir. Nitekim annenin eğitim düzeyi yüksek olsa bile fiziksel aktiviteye yönelik tutumu düşükse çocukların da bu durumdan olumsuz etkileneceği söylenebilir.

Araştırma sonuçlarına göre katılımcıların sosyal görünüş kaygısı düzeyleri baba eğitim durumuna göre anlamlı bir şekilde farklılaşmamaktadır. Bu sonuca paralel olarak Alımcı (2018), Çetinkaya vd. (2019) ve Şahin (2018) tarafından yapılan çalışmalarda da katılımcıların sosyal görünüş kaygısı düzeylerinin baba eğitim durumuna göre farklılaşmadığı belirlenmiştir. Bunun yanı sıra Özkan (2017) tarafından yapılan çalışmada ise baba eğitim durumu okur-yazar olmayan katılımcıların sosyal görünüş kaygısı düzeylerinin, baba eğitim durumu lise ve üniversite olan katılımcılardan daha yüksek olduğu, baba eğitim durumu arttıkça sosyal görünüş kaygısının azaldığı sonucuna ulaşılmıştır. Öte yandan Kahıyah ve Yarım (2020) tarafından yapılan çalışmanın sonucuna benzer olarak katılımcıların fiziksel aktiviteye katılım motivasyonu algılarının baba eğitim durumuna göre anlamlı bir şekilde farklılaşmadığı tespit edilmiştir. Bunun aksine Mutlu Bozkurt ve Tamer (2020) tarafından yapılan çalışmada ise baba eğitim düzeyi arttıkça fiziksel aktiviteye katılım motivasyonunun da arttığı tespit edilmiştir. Toplumsal anlamda ataerkil bir yapıya sahip olmamız nedeniyle babaların daha çok evin geçiminden sorumlu olması, çocuklarıyla çok fazla vakit geçirememeleri, serbest zamanlarını değerlendirme biçimleri bu bulgunun ortaya çıkmasında etkili olabilir.

Son olarak çalışma sonuçları sosyal görünüş kaygısı ve fiziksel aktiviteye katılım motivasyonu arasında negatif yönde ve orta düzeyde anlamlı bir ilişki olduğunu göstermektedir. 
Akkuş, Türk ve Akkuş Aydemir (2019) tarafından yapılan çalışmada fiziksel aktivite ve sosyal görünüş kaygısı arasında pozitif ilişki tespit edilmiştir. Öte yandan Alemdağ ve Öncü (2015) yaptıkları çalışmada fiziksel aktiviteye katılım arttıkça sosyal görünüş kaygısının azaldığını; Kalemoğlu Varol vd. (2014) beden eğitimine yönelik tutum arttıkça sosyal görünüş kaygısının azaldığını tespit etmiş̧lerdir. Fiziksel aktiviteye katılımla birlikte kişilerin daha atletik bir yapıya sahip olmalarının kendilerini daha iyi hissetmelerine ve fiziksel görünüşlerinden daha çok memnun olmalarına olanak sağladığı söylenebilir. Fiziksel görünümden memnun olan kişilerin de daha düşük sosyal görünüş kaygısı yaşadıkları söylenebilir.

Bu çalışmanın iki ilde ve sınırlı sayıda örneklem üzerinde ve sadece kız öğrenciler üzerinde yürütülmüş olması çalışmanın sınırlılıkları arasında gösterilebilir. İlerde yapılacak çalışmalar daha geniş ve farklı karakterdeki örneklem grupları üzerinde yürütülebilir. Ayrıca benzer çalışmaların farklı bağımlı ve bağımsız değişkenler açısından ele alınmasının konunun daha iyi anlaşılmasını sağlayacağı düşünülmektedir. Bunun yanı sıra ilerde yapılacak çalışmalar, konu hakkında daha fazla fikir sahibi olmaya yardımcı olma açısından nitel yaklaşım ya da karma yaklaşım çerçevesinde ele alınabilir.

\section{Kaynakça}

Akkuş, Y., Türk, R. ve Akkuş Aydemir, A. (2019). Sağlıklı yaşam biçimi davranışları ile sosyal görünüş kaygısı arasındaki ilişkinin incelenmesi. Sağllk Bilimleri ve Meslekleri Dergisi, 6(1), 120-126.

Alemdağ, S. ve Öncü, E. (2015). Öğretmen adaylarının fiziksel aktiviteye katılım ve sosyal görünüş kaygilarının incelenmesi. International Journal of Science Culture and Sport, 3, 287-300.

Alımc1, D. (2018). Ortaokul ögrencilerinin akran zorbalı̆̆g ve sosyal görünüş kaygıları ile kendine saygıları arasındaki ilişkinin incelenmesi. (Yayınlanmamış yüksek lisans tezi). İstanbul Sabahattin Zaim Üniversitesi, İstanbul.

Arslan, A. (2019). Sağlık hizmetleri meslek yüksekokulu öğrencilerinin sosyal kaygıları ve genel özyeterlik algılarının çeşitli değişkenler açısından incelenmesi. International e-Journal of Educational Studies, 3(6), 78-96.

Beesdo, K., Knappe, S. \& Pine, D. S. (2009). Anxiety and anxiety disorders in children and adolescents: Developmental issues and implications for DSM-V. Psychiatr Clin North Am, 32(3), 483-524.

Bilge, F. ve Kellecioğlu, H. (2008). Psychometric properties of the brief fear of negative evaluation scale Turkish form. Eurasian Journal of Educational Research, 32, 21-25.

Büyüköztürk, Ş. (2012). Sosyal bilimler için veri analizi el kitabı. Ankara: Pegem Akademi.

CDC [Centers for Disease Control and Prevention]. (2010) The association between school based physical activity, including physical education, and academic performance. Atlanta, U.S. Department of Health and Human Services. 
Clark, L. \& Tiggemann, M. (2006). Appearance culture in nine- to 12-year-old girls: Media and peer influences on body dissatisfaction. Social Development, 15(4), 628-643.

Crome, E., Grove, R., Baillie, A. J., Sunderland, M., Teesson, M. \& Slade, T. (2015). DSM-IV and DSM-V social anxiety disorder in the Australian community. Australian and New Zealand Journal of Psychiatry, 49(3), 227-235.

Çakır, E. (2019). Lise öğrencilerinin fiziksel aktiviteye katılım motivasyonları ile vücut kitle indeksi arasındaki ilişkinin incelenmesi. Atatürk Üniversitesi Beden Eğitimi ve Spor Bilimleri Dergisi, 21(1-A).

Çetinkaya, B., Gülaçtı, F. ve Çiftci, Z. (2019). Lise öğrencilerinin sosyal görünüş kaygı düzeylerinin bazı değişkenlere göre incelenmesi. Uluslararası Toplum Araştırmaları Dergisi, 10(17), 905922.

Çınar, H. ve Keskin, N. (2015). Öğrencilerin sosyal görünüş kaygısının öğrenim yeri tercihlerine etkisi. Electronic Journal of Vocational Colleges, 14, 457-464.

Demir, İ. (2009). Gençlerin kimlik statülerinin kültürel karş1laştırması: İstanbul-Nusaybin örneği. Çocuk ve Gençlik Ruh Să̆lı̆̆ı Dergisi, 16(3), 129-136.

Doğan, T. (2010). Sosyal görünüş kaygısı ölçeğinin (SGKÖ) Türkçe uyarlaması: Geçerlik ve güvenirlik çalışması. Hacettepe Üniversitesi Ë̆itim Fakültesi Dergisi, 39, 151-159.

Doğan, T. (2011). Sosyal görünüş kaygısı ölçeğinin psikometrik özelliklerinin ergenlerden oluşan bir örneklemde incelenmesi. Illkögretim Online, 10(1), 12-19.

Eime, R. M, Young, J. A., Harvey, J. T., Charity, M. J. \& Payne, W. R (2013). A systematic review of the psychological and social benefits of participation in sport for children and adolescents: Informing development of a conceptual model of health through sport. International Journal of Behavioral Nutrition and Physical Activity, 10(98), 2-21.

Erdoğan, Ö. ve Tütüncü, İ. (2015). Üniversite öğrencilerinin beden algısı, yeme tutumu ve yakın ilişki kurma düzeyleri arasındaki ilişki. SSTB International Refereed Academic Journal of Sports, Health \& Medical Sciences, 17, 89-115.

Eren Gümüş, A. (2010). Sosyal kaygı ile başa çıkma. Ankara: Nobel Yayın Dağıtım.

Görker, I., Korkmazlar, Ü., Durukan, M. ve Aydoğdu, A. (2004). Çocuk ve ergen psikiyatri kliniğine başvuran ergenlerde belirti ve tanı dağılımı. Klinik Psikiyatri, 7, 103-110.

Gültekin, Ş. (2019). 15-18 yaş grubundaki ergenlerin akıllı telefon bağımlılı̆̆l ve olumsuz değerlendirilme korkusunun incelenmesi. (Yayınlanmamış yüksek lisans tezi). Ankara Yıldırım Beyazıt Üniversitesi, Ankara.

Hart, E. A., Leary, M. R. \& Rejeski, W. J. (1989). The measurement of social physique anxiety. Journal of Sport and Exercise Psychology, 11, 94-104.

Hart, T. A., Flora, D. B., Palyo, S. A., Fresco, D. M., Holle, C. \& Heimberg, R. G. (2008). Development and examination of the social appearance anxiety scale. Assessment, 15(1), 48-59.

Kahıyah, A. M. H. ve Yarım, İ. (2020). Arap okullarında okuyan öğrencilerin fiziksel aktiviteye katılım motivasyon düzeylerinin bazı değişkenlere göre karşılaştırılması. TURAN-SAM Uluslararası Bilimsel Hakemli Dergisi, 12(47). 
Kalafat, T. (2006). Üniversite ögrencilerinin beden memnuniyeti düzeyleri ile sosyal beceri düzeyleri arasındaki ilişkinin incelenmesi. (Yayımlanmamış yüksek lisans tezi). Çanakkale Onsekiz Mart Üniversitesi, Çanakkale.

Kalemoğlu Varol, Y., Erbaş, M. K. ve Ünlü, H. (2014). Ergenlerin sosyal görünüş kaygılları ile beden eğitimi dersine yönelik tutumları arasındaki ilişki. Niğde Üniversitesi Beden Ĕgitimi ve Spor Bilimleri Dergisi, 8(1), 121-130.

Karacabey, K., Apur, U., Öntürk, Y. ve Akyel, Y. (2017). Ergen sporcuların kayg1 ve kendine güven düzeylerinin bazı değişkenler açısından incelenmesi: Sporcu eğitim merkezleri örneği. Batman Üniversitesi Yaşam Bilimleri Dergisi, 7(2/1), 111-121.

Karasar, N. (2012). Bilimsel araştırma yöntemi. Ankara: Nobel Akademik Yayıncılık.

Kılıç, M. ve Karakuş, Ö. Üniversite öğrencilerinin sosyal görünüş kaygıları ile benlik saygıları ve yalnızlık düzeyleri arasındaki ilişkinin incelenmesi. Journal of Human Sciences, 13(3), 38373852.

Koyuncu, A. (2012). Sosyal fobi. İstanbul: Liman.

Kring, A. M., Davison, G. C, Neale, J. M. \& Johnson, S. (2015). Anormal psikolojisi. M. Şahin (çev.), Ankara: Nobel Akademi.

Kulaksızoğlu, A. (2011). Ergenlik psikolojisi. İstanbul: Remzi Yayınevi.

La Greca, L. J. \& Lopez, N. (1998) Social anxiety among adolescents: Linkages with peer relations and friendships. Journal of Abnormal Child Psychology, 26, 83-94.

Leahy, R. \& Holland, S. (2009). Depresyon ve kaygı bozukluğu tedavi planları ve girişimleri. S. Alsan, E. Köroğlu, H. Türkçapar (Çev.). Ankara: HYB Yayınları.

Matera, C., Nerini, A. \& Stefanile, C. (2013). The role of peer influence on girls' body dissatisfaction and dieting. European Review of Applied Psychology, 63(2), 67-74.

Meydanlığlu, A. (2015). Çocuklarda fiziksel aktivitenin biyopsikososyal yararları. Psikiyatride Güncel Yaklaşımlar, 7(2), 125-135.

Mills, A. C., Grant, D. M., Judah, M. R. \& Lechner, W. V. (2014). Consequences of anticipatory processing on cognitive symptoms of social anxiety. Anxiety, Stress \& Coping, 27(4), 394-409.

Mutlu Bozkurt, T. ve Tamer, K. (2020). Fiziksel aktiviteye katılım motivasyonu düzeyi. Gaziantep Üniversitesi Spor Bilimleri Dergisi, 5(3), 286-298.

Nachmias, C. F. \& Nachmias, D. (1996). Research methods in the social sciences. (5th Ed.) New York: St. Martin's Press.

Norton, A. R., Abbott, M. J., Norberg, M. M. \& Hunt, C. (2015). A systematic review of mindfulness and acceptance-based treatments for social anxiety disorder. Journal of Clinical Psychology, 71(4), 283-301.

Özdemir, R. A., Çuğ, M. ve Çelik, Ö. (2010). Effects of different exercise interventions on social physique anxiety in young adult male university students. Hacettepe Journal of Sport Sciences, $21(2), 60-70$. 
Özkan, Y. (2017). Ergenlerde sosyal görünüş kaygısı ile duygusal yeme arasındaki ilişsinin incelenmesi. (Yayınlanmamış yüksek lisans tezi). İstanbul Gelişim Üniversitesi, İstanbul.

Schniering, C. A., Hudson, J. L. \& Rapee, R. M. (2000). Issues in the diagnosis and assessment of anxiety disorders in children and adolescents. Clin Psychol Rev, 20, 453-478.

Seki, T. (2014). Ergenlerin sosyal görünüş kaygısı ve öznel iyi oluşlarının sahip oldukları değerler açısından incelenmesi. (Yayınlanmamış yüksek lisans tezi). Necmettin Erbakan Üniversitesi, Konya.

Senna, Y. E. (2019). Ortaöğretim öğrencilerinin fiziksel aktiviteye yönelimlerinin, sosyal görünüş kaygısı ve öz yeterlikleriyle ilişkisinin incelenmesi. (Yayınlanmamış yüksek lisans tezi). Ankara Üniversitesi, Ankara.

Soylu, Y., Atik, F. ve Öçalan, M. (2017). Ergenlerin sosyal görünüş kaygısı düzeylerinin incelenmesi. Sportif Bakış: Spor ve Eğitim Bilimleri Dergisi, ÖS(1), 38-45.

Strauss, R. S., Rodzilsky, D., Burack, G. \& Colin, M. (2001) Psychosocial correlates of physical activity in healthy children. Arch Pediatr Adolesc Med, 155(8), 897-902.

Şahin, D. (2018). Ortaöğretim kurumlarına devam eden 14-18 yaş arası ergenlerin anne baba tutumları ve öz anlayışlarının sosyal görünüş kaygılarına etkisi. (Yayınlanmamış yüksek lisans tezi). Gazi Üniversitesi, Ankara.

Tarhan, S. (1995). Lise ögrencilerinin beden imajlarından hoşnut olma düzeylerinin öz-saygıları ve akademik başarıları üzerindeki etkisi. (Yayınlanmamış yüksek lisans tezi). Hacettepe Üniversitesi, Ankara.

Tekkurşun Demir, G. ve Cicioğlu, H. İ. (2019). Fiziksel aktiviteye katılım motivasyonu ile dijital oyun oynama motivasyonu arasındaki ilişkinin incelenmesi. Spormetre, 17(3), 23-34.

Tekkurşun Demir, G. ve Cicioğlu, İ. (2018). Fiziksel aktiviteye katılım motivasyonu ölçeği (FAKMÖ): Geçerlik ve güvenirlik çalışması. International Journal of Human Sciences, 15(4), 2479-2492.

Tekkurşun Demir, G. ve İlhan, E. L. (2019). Engelli sporcularda spora katılım motivasyonu. Ankara Üniversitesi Ĕ̈itim Bilimleri Fakültesi Özel Eğitim Dergisi, 21(1), 49-69.

Türkeli, A. ve Namlı, S. (2019). Beden eğitimi ve spor bölümü öğrencilerinin fiziksel aktivite motivasyonlarının incelenmesi. K. Aydın ve Z. Sakhi (Ed.), İksad 4. International Congress of Social Sciences içinde (s. 12-19).

Türker, A., Er., Y., Yavuz Eroğlu, S., Şentürk, A. ve Durmaz, M. (2018). Spor yapan bireylerin sosyal görünüş kaygısı ve benlik saygısının incelenmesi. Muş Alparslan Üniversitesi Uluslararası Spor Bilimleri Dergisi, 2(1), 8-15.

Türkiye Fiziksel Aktivite Rehberi. (2014). Türkiye Halk Sağlığı Kurumu, 940, Ankara.

Ümmet, D., Çağlar, A., İme, Y. ve Akyıl, Y. (2018). Duygusal özerklik ve olumsuz değerlendirilme korkusunun ergenlerin psikolojik sağlamlığ üzerindeki rolünün incelenmesi. C. Şahin (Ed.), 20. Uluslararası Psikolojik Danışma ve Rehberlik Kongresi içinde (s.288-289).

Vatansever, S. (2017). Lisansl spor yapan ve yapmayan ergenlerin mental iyi oluş, benlik saygısl, sosyal görünüş kaygısı ve algılanan sosyal destek açısından karşılaştırılması. (Yayınlanmamış yüksek lisans tezi). İstanbul Arel Üniversitesi, İstanbul. 
Verhulst, F. C., Ende, J., Ferdinand, R. F. \& Kasius, M. C. (1997). The prevalence of DSMIII- R diagnoses in a national sample of Dutch adolescents. Arch Gen Psychiatry, 54, 329-336.

Vural, M., Keskin, N. ve Çoruh, Y. (2017). Research of social appearance anxiety and self-efficacy of the students entered university by special talent exam. International Journal of Environmental \& Science Education, 12(9), 2063-2071.

Yılmaz, N. (2015). Obez bireylerde benlik saygısl, sosyal görünüş kaygısı ve vücut algısı. (Tıpta uzmanlık tezi). Dokuz Eylül Üniversitesi, İzmir.

Yüceant, M. (2013). Beden eğitimi öğretmen adaylarının sosyal görünüş kaygı düzeylerinin farklı değiş̧kenler açısından incelenmesi. (Yayınlanmamış yüksek lisans tezi). Aksaray Üniversitesi, Aksaray. 